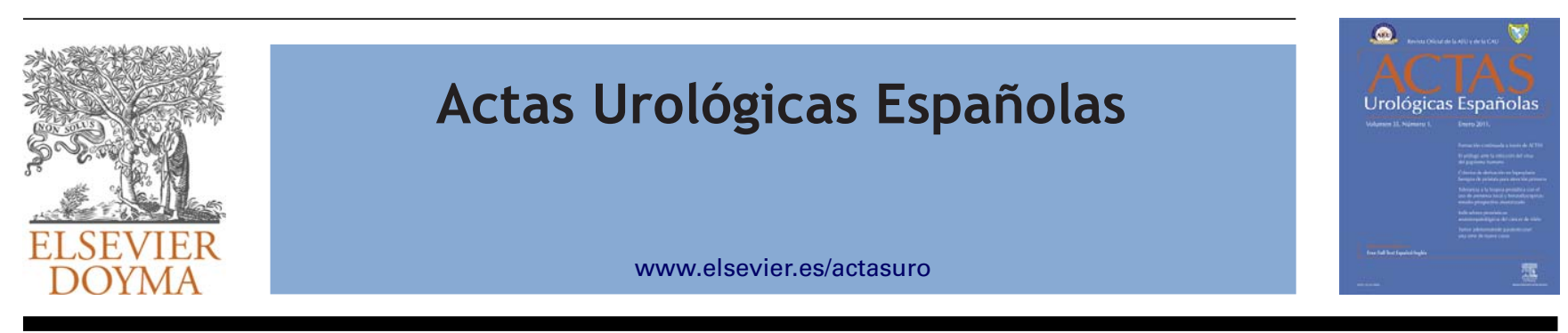

\title{
Aires de cambio
}

\author{
Wind of change
}

Cien años en la vida de una sociedad científica permiten alcanzar madurez y éxito a la par. La Asociación Española de Urología cumple su primer centenario y es consciente hoy, más que nunca, de su historia y de su papel en la Urología mundial y de su responsabilidad con la Urología de habla española en este mundo globalizado en el que nos toca vivir. Actas Urológicas Españolas ha acompañado a nuestra Asociación en sus últimos 33 años, y en su más reciente andadura camina también de la mano de la Confederación Americana de Urología. No siempre fue fácil. Los cuatro directores que me han precedido han servido con dedicación absoluta a la revista sus mejores años de carrera académica y han velado por el nombre y calidad de lo que es Actas Urológicas Españolas hoy, la mejor revista de Urología escrita en español.

Nacimos con Carlos Alférez Villalobos y poco a poco adquirimos entidad (1977-1986), que luego Óscar Leiva Galvis convirtió en divulgación y prestigio (1986-1995). Joaquín Carballido Rodríguez inició lo que podemos llamar etapa "científica", que llegó a desarrollar plenamente José Luis Ruiz Cerdá, entrando así en una nueva etapa más "técnica". . José Luis ha sido un magnífico Director para Actas Urológicas Españolas. Ha conseguido cosas que 8 años atrás eran totalmente impensables. Actas se encuentra hoy, a pesar del limitante inherente a nuestra lengua natal, en todas las bases de datos de primera línea del mundo editorial. Pronto recogeremos los frutos de su trabajo y de los co-Directores y miembros del Comité editorial que le ayudaron en esa dura tarea ${ }^{2}$. El impacto que esperamos alcanzar será, sin duda alguna, su mérito personal y servirá como ofrenda y reconocimiento obligado a quienes le precedieron en su labor. Ésta es la mejor forma de rendir tributo a nuestra historia.

Pero ahora debemos pensar en el futuro, y no en el pasado. Debemos tomar el testigo y conseguir que Actas sea la revista de la que todos nosotros, miembros de la Asociación Española de Urología y miembros de la Confederación Americana de Urología, estemos orgullosos. Por eso debemos afrontar de manera directa nuestros problemas y buscar las mejores soluciones.
Como baluarte científico de la Urología en castellano tenemos un mercado activo de 34 países en los que se habla nuestra lengua, en diferentes soportes y condiciones. La inclusión en castellano y en inglés en SCI-E, JCR, MEDLINE, EMBASE y Excerpta nos coloca a la misma altura que una revista en lengua inglesa, pero con el beneficio de tener además nuestro propio mundo en español. Para conseguir esta situación fueron necesarias importantes acciones humanas y económicas llevadas a cabo por mis predecesores, orientadas a mejorar la periodicidad y puntualidad, y a articular un sistema fiable en las reglas del juego: el proceso editorial. Elsevier España, S.L., es la filial española de la principal firma editorial global en la actualidad y permite una producción sistematizada, de elevada calidad técnica, y el potencial crecimiento en la distribución de la revista siguiendo los cauces y condiciones determinados por la empresa. Pero debemos ser conscientes que la inclusión en las bases de datos de gran escala nos obliga a producir dos revistas (full text español/inglés) en tres formatos diferentes (uno en papel y dos on-line) y que los costes de esta producción son astronómicos.

Pero éste no es el principal problema que tenemos. La realidad es que acabado el 2010 hemos de admitir que algunos de los planteamientos principales del plan estratégico planteado en el 2008 no se han cumplido, o se han cumplido sólo en parte. No se ha conseguido alcanzar una línea editorial y personalidad propia de la revista. La línea de actuación dedicada a mejorar el servicio a los usuarios tampoco tiene un servicio diferencial notorio. La calidad de los artículos no se percibe mejorada por el lector, puesto que la tasa de rechazo de manuscritos en el pasado ha sido muy baja. Por otro lado tenemos que reforzar mejor el compromiso institucional con la Confederación Americana de Urología. Cabe la posibilidad de que nos hayamos preocupado mucho en la visibilidad de nuestra revista, en mejorar la calidad formal para obtener nuestro primer impacto, en favorecer auto-citación, pero que no se haya dedicado el esfuerzo suficiente para mejorar la calidad científica/técnica, el aspecto y la imagen de Actas; en definitiva, el compromiso. Nos faltan artículos y autores de calidad que 
generen cuantiosa citación: artículos originales de ciencia básica, estudios originales realmente novedosos, publicación de ensayos clínicos o grupos de colaboración... No podemos seguir publicando Notas científico-clínicas, Imágenes u otros materiales de nulo impacto que implican un coste inaceptable.

Francesco Montorsi describió su labor en el European Urology como que precisa más tiempo cuidar una revista que un matrimonio ${ }^{3}$, y creo que tiene razón. Necesitamos impacto, sí, pero antes necesitamos imagen y calidad. Un urólogo joven debe de estar deseoso de recibir "su" revista, la que le garantizará formación técnica y científica. Un urólogo entrado en años debe disfrutar al ver que puede seguir perfectamente la edición de "su" revista y estar al día en la especialidad. Un académico debe estar orgulloso al ver que el grupo de trabajo que lidera está bien representado en "su" revista, con artículos completos y de gran calidad. Luego lo demás vendrá sin sufrimiento. Calidad está reñida con cantidad. Siento decir que debemos aumentar la tasa de rechazo para que la calidad técnica, expositiva y formativa de Actas genere verdadera citación. Necesitamos nuevas instrucciones, nuevos revisores y nuevas directrices. Por ello, juntos, vamos a conseguir que estos cambios conviertan a Actas en la mejor revista urológica en español de manera indiscutible.

Las nuevas instrucciones para autores van encaminadas a reducir la tara de nuestra revista. Eso no significa que los residentes a partir de ahora no puedan publicar, ni mucho menos; lo que significa es que en Actas no se podrá publicar sin esfuerzo, o con poco esfuerzo, y que seguramente se publicarán menos cosas pero de mayor calidad. El comité editorial no puede caer en la rutina, sino que debe ser dinámico y activo. Actas no puede depender de personas que tardan más de un mes en abrir sus respectivos correos y en aceptar una evaluación, ni tampoco de personas ocupadas a las que se les olvida hacerlo. El proceso editorial debe acortarse y debe hacerse con la misma seriedad que a uno le gustaría que recibiese sus propios manuscritos. Con sensibilidad, con eficacia y con firmeza. Más vale un "no" a tiempo que una frustración diferidamente escurridiza. Pero los autores también deben poner de su parte. Un manuscrito es una obra de arte que además perdura para siempre en el mundo del conocimiento. Por ello, puesto que es lo que de nosotros verán nuestros descendientes urológicos cuando aquí ya no estemos, un manuscrito debe ser perfecto. Debe estar escrito a conciencia, con las imágenes apropiadas, con una secuencia lógica y expositiva admirable, con unos resultados claros y ordenados, con una verificación intachable de la hipótesis y una metodología purista, con un idioma exquisito, con estilo y con gracia. En fin, que debe ser sublime. $Y$ como no caben las chapuzas en una revista de prestigio Actas velará por la estricta calidad de sus contenidos a la par que los autores cuidarán la calidad de su trabajo en todos los aspectos.

A los autores se les va a pedir dedicación para publicar mejor, pero también se les va a dar un proceso editorial dinámico, justo y efectivo. Vamos a acortar el proceso y a ser más rigurosos. Daremos el mismo trato a todos, y será el mismo trato que a nosotros nos gusta recibir. A partir de ahora se compite por el espacio. Un manuscrito optará a ser publicado no sólo si está lo suficientemente bien, sino sólo si es mejor que el resto de manuscritos que tiene a su lado, puesto que de los más de 400 que se reciben al año sólo publicaremos en torno a 120. Cuanto más competitivos sean los manuscritos mejor será el resultado. Debemos potenciar al máximo segundas y terceras vueltas de proceso editorial. Los autores han de acostumbrarse a varias circunstancias que antes no solían darse; pongamos algunos ejemplos. De entrada un manuscrito que no cumpla la normativa para autores o que esté deficientemente escrito no debe remitirse a revisores, sino que se rechazará automáticamente. Por otro lado, un manuscrito que esté bien escrito y que sea oportuno, pero no lo suficientemente interesante $o$ atractivo, puede rechazarse también sin ser enviado a revisores debido a la competencia existente por un espacio publicable limitado. Los autores tienen derecho a conocer esta situación lo antes posible para que, si lo estiman oportuno, envíen su trabajo a otras revistas.

Todo manuscrito con talento, que sea potencialmente mejorable, deberá acceder al proceso editorial por revisores pareados antes de que se tome una decisión acerca de su eventual publicación; y esta premisa incluye a todo tipo de autor. Los revisores de Actas no serán uno o dos por artículo. Se enviará el manuscrito ciego al menos a tres, y en ocasiones a 5 revisores. Un manuscrito en el que los revisores soliciten cambios (menores o mayores) deberán ser cumplidos. Ya se han articulado los mecanismos para velar por el cumplimiento de dichas correcciones y mejoras. El que un manuscrito haya superado el rechazo directo no implicará que no pueda ser rechazado en una segunda o incluso tercera revisión. Se articulará hasta una cuarta versión revisada (R4) si fuera necesario. La redacción de la revista (director, traductor y correctores) pueden y deben hacer cambios necesarios en los manuscritos hasta que se alcance la unidad y calidad expositiva deseada, en aras de la brevedad y del buen consumo de nuestro principal recurso: el espacio editorial. Es responsabilidad de los autores verificar las pruebas de sus trabajos. Por desgracia muchos se olvidan cuando reciben la contestación de "aceptado" de revisar el fruto final del proceso editorial, y eso también resta calidad a Actas.

En resumen, haremos lo mismo que se ha hecho hasta ahora, pero con más rectitud, exigencia y dedicación. Es la mejor forma que tenemos de expresar el respeto por el trabajo de las personas, dar lo mejor de nosotros para que su artículo sea una "obra de arte"'. La citación cualificada, el incremento del impacto y el reconocimiento vendrán solos a medida que aumente nuestro deseo de publicar en Actas y la satisfacción por conseguirlo.

La revista tiene muchas necesidades. Hemos establecido un órgano nuevo, un comité asesor compuesto por personas de reconocido prestigio y con gran dedicación al trabajo que velará en exclusividad por vigilar que la reforma que necesitamos se lleve a cabo de manera firme y con perspectiva amplia. Vamos a reestructurar el comité de revisores, contando con quienes desde la experiencia y dedicación deseen dar parte de su tiempo para llevar esta empresa a su mejor fin. A fin de año se agradecerá personal y públicamente el trabajo realizado, tal y como corresponde. Los revisores han de ser exigentes y hacer bien su trabajo para que la circunstancia de publicar manuscritos que no dan la talla, mientras se rechacen manuscritos de mayor interés, suceda sólo excepcionalmente o nunca. 
Actas debe aspirar a la autogestión económica y, por ello, todos debemos ser conscientes de que espacio editorial se traduce en dinero, y de que el dinero de todos lo debemos emplear de la manera más responsable posible. Debemos tener una actitud de servicio a los urólogos y a los amigos de la Urología: departamentos universitarios, unidades de investigación, industria farmacéutica y de tecnología sanitaria, gestores sanitarios, especialidades afines, etc. Sólo así haremos posible el cambio hacia la mejora global de la calidad editorial, sirviendo a la Asociación Española de Urología y a la Confederación Americana de Urología de las que somos órgano oficial.

Muchas gracias a la Junta Directiva de la Asociación Española de Urología por depositar en este servidor su confianza.

\section{Bibliografía}

1. Carballido J, Ruiz Cerdá JL. La hora del relevo. Actas Urol Esp. 2004;28:1-3.

2. Ruiz Cerdá JL. Nuevo organigrama directivo de Actas Urológicas Españolas. Actas Urol Esp. 2009;33:1.

3. Montorsi F. Three platinum years at European Urology: Keys to success and future perspectives. Eur Urol. 2008;54:1209-13.

J.C. Angulo

Director de Actas Urológicas Españolas, Jefe de Servicio de Urología, Hospital Universitario de Getafe, Madrid, España

Correo electrónico: jangulo@futurnet.es, jangulo.hugf@salud.madrid.org

Disponible en Internet el 5 de enero de 2011 